\title{
Zuckerman's Alternative Five Factor Model and Risk Taking Behavior
}

\author{
Pradeep $\operatorname{Kumar}^{1 *}$, Umed Singh ${ }^{2}$
}

\section{ABSTRACT}

This study was designed to investigate the relationship between risk taking behavior/perception and five factors of personality (AFFM). To realize the main objective of the study DomainSpecific Risk-Taking Scale and Zuckerman-Kuhlman Personality Questionnaire were administered on a group of 57 subjects ranging in age from 18 to 24 years. Obtained data was analyzed by using descriptive statistics and Pearson's correlations. Correlational analysis revealed Activity and Sociability to be positively correlated with all the five domains of risk taking behavior/perception i.e. Ethical, Financial, Health/Safety, Recreational and Social. Neuroticism-Anxiety has correlated negatively with Financial, Health/Safety, and Recreational domains of risk taking. Aggression-Hostility has correlated negatively with Health/Safety. Impulsive-Sensation Seeking has corresponded positively with domains of risk taking viz Financial, Health/Safety and Social.

Keywords: Risk Taking Behavior, Personality, AFFM

Risk-taking behavior refers to the tendency to engage in such types of behaviors that have the potential to be harmful or dangerous, yet at the same time provide the opportunity for some kind of outcome that can be perceived as positive. It is defined and studied in different perspectives. It has been explained as "understanding a task involving a challenge for achievement or desirable goal in which there is a lack of certainty or a fear of failure (CCA, 2008). It also includes exhibiting certain behaviors whose outcomes may present a risk to the individual and/or to those associated with him or her." Zuckerman and Kuhlman (2000) suggested that when we say "weigh", “consider", or "think about”, we are really about the early stages of risk-taking activities. These researchers also suggested that decision-making process can be changed after a risk leads to punishment. Whatever, now a days, yet, there is no single definition of risk taking behavior because the concept of risk is treated in different areas of knowledge. Hence, the term risk does not have a unitary meaning and interpretation (Goma-i-Freixanet, 2004).

Regarding the different areas of risky behavior, there are number of theories which try to describe the risk behavior. Such as in the context of field of international relations and polities;

\footnotetext{
${ }^{1}$ Research Scholar, Department of Psychology, K.U. Kurukshetra.

${ }^{2}$ Professor, Department of Psychology, K.U. Kurukshetra.

*Corresponding Author

(C) 2015 I P Kumar, U Singh; licensee IJIP. This is an Open Access Research distributed under the terms of the Creative Commons Attribution License (http://creativecommons.org/licenses/by/2.0), which permits unrestricted use, distribution, and reproduction in any Medium, provided the original work is properly cited.
} 


\section{Zuckerman's Alternative Five Factor Model and Risk Taking Behavior}

prospect theory provides a new insight into risky decision-making (Levy 1992, 1997). According to this theory, decision makers accept risks to make comparable gains. So, this theory describes the risky behavior in relation to how problems are framed. Another theory proposed by Weinstein (1980) that describes the risky behavior in the context of people's belief that they are invulnerable which means expectation that misfortunes happen to others and not ourselves. This theory covers the wide range of health and other area of risky behavior. Smith and Apter (1975) proposed the 'reversal theory' which is related with motivation and describe the risky behavior in relation to connections between arousal level, the subjective perception of emotion, the influence of social context, and behavior. So, this theory is related with phenomena that is not essential for human survival but is voluntarily undertaken (Apter \& Batler, 1997). To measure the risky behavior, so many instruments have been prepared. In the present investigation, Domain-Specific Risk-Taking Scale (DOSPERT) is used which is based on five content domains, i.e., ethical, financial (can be further decomposed into gambling and investment), health/safety, social, and recreation (Weber et al., 2002).

Review of literature revealed that none of these theories take individual differences in personality into account. Regarding the individual differences, one early trait theory described by Zuckerman et al. (1964). The theory of Sensation Seeking which is based on assumptions that there are consistent individual differences in optimal levels of stimulation and arousal. Investigators explored the relationship between Sensation Seeking and different areas of risky behavior such as potentially risky experiments, sports, vocations, criminal activities, sexual behavior, smoking, heavy drinking, reckless driving, driving under the influence of alcohol, gambling, chronic substance dependence, vulnerability to drug use, age of onset and cooccurring psychiatric disorders (Zuckerman, 1979a; 1994a; Kaestner et al. 1977; Montey \& Birenbaum 1986; Sutker et al. 1978, 1979). Eysenck (1976) asserted that both extraversion and psychoticism are related to risky behavior such as "promiscuity". Similarly, the relationship between personality factors of Five Factor Model and risk-taking in adolescents and adults are explored. Neuroticism, agreeableness, and conscientiousness are strongly related with pathological gambling (Меcca, 2003); and neuroticism and conscientiousness are with sexual risk-taking behavior (Hoyle et al. 2000). Alternative Five Factor Model of personality has also been studied in relation to risky behavior suggesting that there is a significant relationship with Impulsive Sensation Seeking, Aggression-Hostility, and Sociability, but not to scales for Neuroticism-Anxiety and Activity (Zuckerman \& Kuhlman; 2000). However, a few studies have been conducted on risky behavior in Indian perspective especially in the context of Alternative Five Factor Model of personality.

For the development of Alternative Five Factor Model (AFFM), Zuckerman (1989) studied the structure underlying 46 scales selected from eight inventories used as measures of temperament or involved in psychobiological studies of personality. The original Big-Five Factor Model was based on lexical analysis of self and other ratings using adjectives rather than a questionnaire. However, some traits which are important across species such as impulsive-sensation seeking and aggression-hostility are not represented in the lexicon analysis to become primary factors. 
These traits have proven to have a high heritability and strong biological correlates (Zuckerman, 1979, 1994, 2006). Alternative Five Factor Model (Zuckerman \& Kuhlman, 1993) explains personality structure in terms of five factors, namely, Neuroticism-Anxiety, Activity, Aggression-Hostility, Impulsive-Sensation Seeking, and Sociability. Neuroticism-Anxiety describes emotional upset and instability, tension, anxiety, lack of self-confidence, and sensitivity to criticism. Activity scale consists of two facets: Need for General Activity which describes a need for activity and tendency to experience impatience and restlessness when being inactive; and Need for Work Effort which describes the tendency to invest a lot of energy for hard work and other tasks. Aggression-Hostility describes the readiness to verbal aggression or rude and antisocial behavior. From Impulsive-Sensation Seeking Scale, two facet scores can be obtained i.e. Impulsivity and Sensation Seeking which describe a need for novelty, change, excitement, lack of planning and acting on impulse. The another factor is Sociability which consists of parties and friends, which describe liking for parties and having a lot of friends; and Isolation Intolerance which describes an intolerance of social isolation. So, the present study is mainly oriented to find out the personality correlates of risk-taking behavior in terms of Alternative Five Factor Model.

\section{METHODOLOGY}

\section{Sample}

57 participants were selected from the various departments of the Chaudhary Ranbir Singh University, Jind ranging in age from 20 to 26 years with the mean age of 23 years consisting of 35 males and 22 females.

\section{Measures}

Following measures were used for data collection.

(1) Domain-Specific Risk-Taking (DOSPERT) Scale (Weber et al. 2002) composed with five content domains, i.e., ethical, financial (can be further decomposed into gambling and investment), health/safety, social, and recreation. The scale includes total 30 items using 7-point rating scale ranging from 1 (Extremely Unlikely) to 7 (Extremely Likely). Regarding the psychometric properties of the scale, moderate test-retest reliability has found. Satisfactory factorial and convergent/discriminant validity have been investigated in respect to construct such as sensation seeking, dispositional risk taking, intolerance for ambiguity, and social desirability. Zuniga and Bouzas (2005) also provided the good construct validity of health/safety and recreational risk-taking subscales in relation to a sample of blood alcohol concentrations.

(2) Zuckerman-Kuhlman Personality Questionnaire (Zuckerman \& Kuhlman, 1993) consists of 5 content scales, plus an infrequency scale that allows eliminating subjects with careless responding. The ZKPQ includes total 99 dichotomous items (in sentence format and true-false response set) that assess the basic dimensions of personality that constitute the Alternative Five Factor Model (AFFM). The five scales can be described in terms of their contents: NeuroticismAnxiety Scale (19items); Activity Scale (17 items); comprises two components, i.e. Need for General Activity and Need for Work Activity; Aggression-Hostility Scale (17 items); Impulsive -Sensation Seeking Scale (19 items); two facet scores can be obtained from this scale i.e. Impulsivity and Sensation Seeking; and Sociability Scale (17 items) contains two sub 
components, i.e. Parties and Friends, and Isolation Intolerance. The test retest reliabilities of the Zuckerman-Kuhlman Personality Questionnaire range from .72 to .84 in American and German samples (Schmitz, 2004). Satisfactory validity has been found, with multi-scale questionnaire for both convergent and discriminant validity within a multi-trait-multi-method matrix (Campbell \& Fiske, 1959).

\section{Procedure}

The investigator contacted to all the students personally in their respective departments and established a rapport for making them acquired with purpose of the study. Then tests were administered strictly following the instructions specified in the respective test manuals.

\section{RESULTS}

Obtained data was analyzed by applying descriptive statistics, and Pearson's Product Method of Correlation. The distribution of scores of variables of personality and risk taking are analyzed along with their means, standard deviations, skewness and kurtoses presented in table 1. Table 1 shows that distributions of scores are almost normal.

Table-1 Descriptive Statistics

\begin{tabular}{|l|l|l|l|l|}
\hline Variables & Mean & SD & Sk & Ku \\
\hline Act & 11.54 & 2.08 & -.16 & .21 \\
\hline N-Anx & 6.42 & 4.12 & .52 & -.39 \\
\hline Agg-Host & 6.74 & 1.78 & .24 & -1.05 \\
\hline Imp-SS & 9.02 & 2.09 & -.39 & -.18 \\
\hline Sy & 8.32 & 1.39 & .27 & -.31 \\
\hline Eth & 20.40 & 5.99 & .24 & .15 \\
\hline Finc & 25.32 & 5.27 & .10 & -1.00 \\
\hline H/S & 22.37 & 7.07 & -.62 & .19 \\
\hline Rec & 27.53 & 6.54 & -.61 & -1.08 \\
\hline SS & 28.26 & 4.39 & -.41 & .55 \\
\hline Com & 24.78 & 5.02 & -.20 & -1.05 \\
\hline
\end{tabular}

Table-2 Correlations Matrix

\begin{tabular}{|l|l|l|l|l|l|l|}
\hline Variables & Eth & Finc & H/S & Rec & SS & Comp \\
\hline Act & $\mathbf{3 5}$ & $\mathbf{5 4}$ & $\mathbf{4 1}$ & $\mathbf{5 5}$ & $\mathbf{3 4}$ & $\mathbf{6 6}$ \\
\hline N-Anx & -24 & $-\mathbf{5 8}$ & $\mathbf{- 4 1}$ & $-\mathbf{3 5}$ & -08 & $\mathbf{- 4 3}$ \\
\hline Agg-Host & -10 & -24 & $\mathbf{- 4 8}$ & -20 & 08 & $-\mathbf{2 8}$ \\
\hline Imp-SS & 22 & $\mathbf{3 4}$ & $\mathbf{3 3}$ & 12 & $\mathbf{4 9}$ & $\mathbf{4 6}$ \\
\hline Sy & $\mathbf{2 6}$ & $\mathbf{3 3}$ & $\mathbf{4 8}$ & $\mathbf{2 6}$ & $\mathbf{7 8}$ & $\mathbf{5 9}$ \\
\hline
\end{tabular}

$\mathrm{r}=.25 \mathrm{p}<.05 ; \mathrm{r}=.33 \mathrm{p}<.01 ;$ decimal points omitted.

Intercorrelations were computed among all the 11 variables. Correlations between two types of measures are ranging from -.58 to .78. Twenty two of 30 correlations are significant above .05 or .01 level of significance of which 16 are positive and 6 significant at or above .05 or .01 levels of 


\section{Zuckerman's Alternative Five Factor Model and Risk Taking Behavior}

significance; of which 16 are positive and 6 are negative. Activity has correlated positively with Ethical $(\mathrm{r}=.35 \mathrm{p}<.05)$, Financial $(\mathrm{r}=.54 \mathrm{p}<.01)$, Health/Safety $(\mathrm{r}=.41 \mathrm{p}<.01), \quad$ Recreational $(\mathrm{r}=.55 \mathrm{p}<.01)$, Social $(\mathrm{r}=.34 \mathrm{p}<.01) \quad$ Scales; and Composite score of risk-taking behavior $(\mathrm{r}=.65 \mathrm{p}<.01)$. Neuroticism-Anxiety has marked significant negative correlation with Financial $(\mathrm{r}=.-58 \mathrm{p}<.01)$, Health/Safety $(\mathrm{r}=.-31 \mathrm{p}<.05)$, Recreational $(\mathrm{r}=.-35 \mathrm{p}<.01)$ Scales; and Composite score $(\mathrm{r}=.-43 \mathrm{p}<.01)$. Aggression-Hostility has marked significant negative relationship with Health/Safety $(\mathrm{r}=.-48 \mathrm{p}<.01)$ and Composite score $(\mathrm{r}=.-28 \mathrm{p}<.05)$ of risk-taking behavior. Impulsive-Sensation Seeking has marked significant positive relationship with Financial $(\mathrm{r}=.34 \mathrm{p}<.01)$, Health/Safety $(\mathrm{r}=.33 \mathrm{p}<.01)$, Social $(\mathrm{r}=.49 \mathrm{p}<.01)$ and Composite score $(\mathrm{r}=.46 \mathrm{p}<.01)$ of risk-taking behavior. Sociability has correlated positively with Ethical $(\mathrm{r}=.26 \mathrm{p}<.05)$, Financial $(\mathrm{r}=.33 \mathrm{p}<.01)$, Health/Safety $(\mathrm{r}=.48 \mathrm{p}<.01)$, Recreational $(\mathrm{r}=.26 \mathrm{p}<.05)$, Social $(\mathrm{r}=.78 \mathrm{p}<.01)$ and Composite score $(\mathrm{r}=.59 \mathrm{p}<.01)$ of risk-taking behavior. Obtained correlations in the present study depict that there is significant relationship between domains of risk-taking behavior and personality factors of Alternative Five Factor Model.

\section{DISCUSSION}

The goal of this study was to find out the relationship between personality factors of Zuckerman's model (1993) and five domains of risk-taking behavior. To realize the research objective of the study, obtained data was analyzed by using descriptive statistics, and Pearson's correlations. Results revealed that there is substantial relationship between five personality factors and five domains of risk-taking behavior. Correlations matrix depicts that Activity and Sociability both are having significant positive relationship with all the five domains as well as composite score of risk-taking behavior. The present finding is confirmatory to earlier findings (Zuckerman \& Kuhlman, 2000; Zuckerman et al., 1993; McGhee et al., 2012). McGhee et al. (2012) have reported significant positive association between Extraversion and risk-taking choices on a sample of preadolescents. Impulsive-Sensation Seeking has been found having positive relationship with Financial, Health/Safety, Social and composite score of risk-taking behavior (Zuckerman, 1987; 1994; Thornquist \& Zuckerman, 1995).

Here the negative relationship of, Neuroticism-Anxiety with Financial, Health/Safety, Recreational and composite score of risk-taking behavior; and also negative of AggressionHostility with Health/Safety and composite score of risk-taking behavior are confirmatory to the earlier findings (Мecca, 2003; Muller, 2000). Though the present findings are convincing but can't be considered as generalized. Hence, for more generalization, large scale studies are required and suggested.

\section{REFERENCES}

Apter, M. J., \& Batler, R. (1997). Gratuitous risk: A study of parachuting. In: S. Svebak, \& M.J. Apter (Eds), Stress and health: A reversal theory perspective (pp. 119-129). Washington, DC: Taylor \& Francis.

Campbell, D.T., \& Fiske, D.W. (1959). Convergent and discriminate validation by the multitraitmultimethod matrix. Psychol. Bull, 58:81-105. 


\section{Zuckerman's Alternative Five Factor Model and Risk Taking Behavior}

Centre for Cancer Education, University of Newcastle (2008). A definition of risk-taking. URL (last checked 26 September 2008). http://cancerweb.ncl.ac.uk/cgi-bin/omd?risk-taking.

Goma-i-Freixanet., M. (2004). Sensation Seeking and Participation in Physical Sports. In: R. M. Stelmack (Eds), On The Psychobiology Of Personality: Essays In Honor Of Marvin Zuckerman. UK.

Hoyle, R. H., Feifar, M. C., \& Miller, J. D. (2000). Personality and sexual risk taking: A quantitative review. Journal of Personality, 68, 1203-1231. doi:10.1111/1467-6494.00132

Kaestner, E., Rosen, L., \& Appel, P. (1977). Patterns of drug abuse: Relationship with ethnicity, sensation seeking, and anxiety. Journal of Consulting and Clinical Psychology, 45, 462468.

Levy, J.S. (1992). Prospect theory and international relations: Theoretical applications and analytical problems. Political Psychology, 13, 283-310.

Levy, J.S. (1997). Prospect theory, rational choice and international relations. International Studies Quarterly, 41,87-112.

McGee, R. L., Ehrler, D. J., Buckhalt, J. A., \& Phillips, C. (2012). The Relation between FiveFactor Traits and Risk-Taking Behavior in Preadolescents. Psychology, Vol. 3 No. 8, 558561.

McCrae, R. R., \& John, O. P. (1992). An introduction to the five-factor model and its applications. Journal of Personality, 60, 175-215.doi:10.1111/j.14676494.1992.tb00970.x

Mecca, D. N. (2003). The relationship between pathological gambling and the Big-Five personality factors. Unpublished master's thesis, New Britain, CT: Central Connecticut State University.

Montag, I., \& Birenbaum, M. (1986). Psychopathological factors and sensation seeking. Journal of Research in Personality, 20, 338-348.

Schmitz, P.G. (2004). On the alternative five factor model: Structures and Correlates, In R.M. Stelmack (ed). On the Psychobiology of Personality: Essays in Honor of Marvin Zuckerman. Amsterdam: Elsevier, pp.65-87.

Smith, K.C.P., \& Apter, M.J. (1975). A theory of psychological reversals. Wilts, UK: Picton Publishing.

Sutker, P.B., Archer, R.P., P. J., \& Kilpatrick, D. G. (1979). Alcoholics and opium addicts: A comparison of personality characteristics. Journal of Consulting and Clinical Psychology, 40, 635-644.

Sutker, P.B., Archer, R.P., \& Allain, A. N. (1978). Drug abuse patterns, personality characteristics, and relationship with sex, race, and sensation seeking. Journal of Consulting and Clinical Psychology, 46, 1374-1378.

Thornquist, M. H., \& Zuckerman, M. (1995). Psychopathy, passive-avoidance learning and basic dimensions of personality. Personality and Individual Differences, 19, 525-534.

Weinstein, N.D. (1980). Unrealistic optimism about future life events. Journal of Personality and Social Psychology, 39, 806-820.

Weber, E. U., Blais, A. R., Betz, E. (2002). A Domain specific risk-attitude scale: Measuring risk perceptions and risk behaviors. Journal of Behavioral Decision Making, 15, 263-290.

Zuckerman, M. (1979). Sensation seeking: Beyond the optimal Level of Arousal. Hillsdale, NJ: Erlbaum.

Zuckerman, M. (1987). Biological connection between sensation seeking and drug abuse. In: J. Engel, \& L. Oreland (Eds), Brain reward systems and abuse (pp. 165-173). New York: Raven Press. 
Zuckerman, M. (1989). Personality in the third dimension: A psychobiological approach. Personality and Individual Differences, 10, 391-418.

Zuckerman, M. (1994). Behavioral expressions and biosocial bases of sensation seeking. New York: Cambridge University Press.

Zuckerman, M. (2006). 'Biosocial bases of sensation seeking'. In T. Canli (ed.), Biology of Personality and Individual Differences. New York: Guilford, pp.7-59.

Zuckerman, M., Kolin, B.A., Price, L., \& Zoob, I. (1964). Development of a sensation-seeking scale. Journal of Consulting Psychology, 477-482.

Zuckerman, M., \& Kuhlman, D. M. (1993). Norms for the Zuckerman-Kuhlman Personality Questionnaire (ZKPQ). Unpublished manuscript.

Zuckerman, M., \& Kuhlman, D.M. (2000). Personality and risk-taking: Common biosocial factors. Journal of Personality, 68, 999-1029.

Zuckerman, M., Kuhlman, D.M., Joirman, J., Teta, P. \& Kraft, M. (1993). A Comparison of three structural models for personality: The big three, the big five, and the alternative five: Journal of Personality and Social Psychology, 65(4): 757-68.

Zuniga, A., \& Bouzas, A. (2005). Actitud hacia el riesgo y consume de alcohol de los adolescented. Working paper.

Retrieved July 17, 2006, from https://decisionsciences.columbia.edu/dospert/index.htm 